\title{
Neonatal Coronavirus 2019 Infection in a tertiary setup of India: A case series
}

\author{
Jinia Saha', Tapas Das ${ }^{2}$, Kaustav Nayek ${ }^{3}$ \\ ${ }^{1,2}$ Resident, ${ }^{3}$ Professor, Department of Pediatrics, Burdwan Medical college, Burdwan, India
}

Covid-19 disease caused by SARS-COV-2 has been a pandemic throughout the world including India. It affects all age groups including children. The disease is much milder among children compared to adults. In neonates, the disease is often mild and has good prognosis. It is still doubtful whether there is vertical transmission to the neonates from infected mothers. Also, it is not proved whether the disease can be transmitted through breast milk. Here we present case reports of three neonates, two of which were born to COVID-19 positive mothers. Rest one got infected at 25 days of life. None of the two infants born to COVID-19 positive were positive at the time of birth. Our observation is similar to the previous studies that COVID-19 has not yet been proved to transmit vertically. One of them contracted the disease on day 7 of life from the mother in spite of strict precautions. It could not be proved whether it was transmitted from breast milk or faulty practice. One of the infants presented with late onset sepsis. All of the infants recovered well and was thriving well on follow up.

Key words: COVID-19; Neonate; Vertical transmission, Mild infection

\section{Access this article online}

Website:

http://nepjol.info/index.php/AJMS DOI: 10.3126/ajms.v12i3.33617

E-ISSN: 2091-0576

P-ISSN: $2467-9100$

Copyright (c) 2021 Asian Journal of Medical Sciences

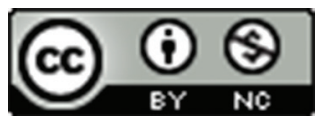

This work is licensed under a Creative Commons Attribution-NonCommercial 4.0 International License.

\section{INTRODUCTION}

Coronavirus disease i.e., COVID-19 caused by severe acute respiratory syndrome coronavirus 2 has led to a worldwide pandemic since its outbreak in Wuhan, China from December 2019. ${ }^{1}$ The disease spreads through person to person contact as well as through infected secretions like respiratory droplets. It affects all age groups and it is seen that disease severity is more in older people and adults with comorbidities like hypertension, diabetes mellitus and chronic lung disease. ${ }^{2}$ It has also been seen that infection in children is mostly milder or asymptomatic. Hospitalization rates are also less compared to adults with minimal casualties. It is possible that the immune system of children might be more resistant against COVID-19. This has been hypothesized due to difference in distribution and maturation of viral receptors in children or it might be due to difference in ACE2 receptor expression in children. ${ }^{3}$ The common symptoms in neonates include fever, gastrointestinal symptoms, hypoxia and cough. ${ }^{4}$

\section{CASE PRESENTATION}

Here we present three cases of neonates born to SARSCOV2 infected mothers whose age was within a month who have been treated in our tertiary hospital and describe the clinical course in these patients. Written consent has been obtained from all the parents of the babies before publishing.

\section{CASE REPORT 1}

We report a 25 days old neonate with Covid-19 infection admitted in our setup. This neonate presented with two days history of fever and cough along with decreased oral intake. The infant was born via vaginal delivery at 
39 weeks of gestation without any complications and she did not have any eventful antenatal course. Mother was 29 years old and gravida 1 para1. The mother along with some of her family members had been diagnosed to be a case of COVID 19 by RT-PCR from nasopharyngeal swab. Mother was negative at the time of her delivery. The baby was exclusively breastfed and was healthy before the illness. The baby was referred to our center and was on supplemental $\mathrm{O} 2$ along with intravenous antibiotics ampicillin and gentamycin.

Physical examination showed the baby was having features of acute respiratory distress with mild upper chest retractions and respiratory rate of $48 /$ minute. SPO2 measurement showed $90 \%$ in room air. HR was $186 \mathrm{bpm}$ and rectal temperature was $101.7^{\circ} \mathrm{F}$. The infant was admitted in NICU with adequate infection control precautions. His vital signs on admission and tests done on hospital course have been summed up in table 1. Blood tests showed leucocytosis with lymphopenia. C-reactive protein was positive and serum lactate dehydrogenase was raised. HRCT scan chest showed bilateral ground glass opacities with perihilar streaking of the lungs [Figure 1]. The baby was started on intravenous fluid of $100 \mathrm{ml} / \mathrm{kg} /$ day along with intravenous antibiotics like piperacillin-tazobactam and meropenem. Hydroxycholoquine at a dose of $5 \mathrm{mg} /$ $\mathrm{kg} /$ day along with azithromycin was started and continued for total 5 days. Mechanical ventilation was started with PEEP of $6 \mathrm{~cm}$ of $\mathrm{H} 20$ and Fi02 of $60 \%$ after obtaining the report of arterial blood gas analysis. The baby slowly improved within 3days and was gradually weaned and extubated thereafter on day 4 and shifted out of NICU on day 7 after proper feeding has been established and no supplemental O2 was needed.
Intravenous antibiotics had been stopped after blood culture report came to be negative. The baby was discharged on day 14 of admission after the repeat test of COVID 19 was negative and the mother was confident to take the baby home. The family was advised for home quarantine and was asked for follow up after 2 weeks to ensure that the baby was thriving well.

\section{CASE REPORT 2}

A term female neonate was born by emergency caesarean section due to fetal distress. The mother was screened for COVID-19 and Rapid antigen test as well as RT-PCR both came out to be positive. The mother was asymptomatic and the baby was a healthy term neonate of $2.76 \mathrm{~kg}$ at birth. RT-PCR of nasopharyngeal swab was sent within 12 hours of birth and it was negative. Breastfeeding was started taking full precautions with mother wearing a mask during baby care as well as hand hygiene practices but on day 7 of life the baby started to have fever spikes along with nasal congestion. RT-PCR of upper nasopharyngeal swab was found to be positive. All other vital parameters were within normal limits and SPO2 was 96\% in room air. Baby was started on azithromycin and hydroxychloroquine for 5days. Intravenous antibiotics ampicillin and gentamycin was started. Fever subsided within a day and baby was feeding normally. Chest X-ray of the newborn was within normal limits. Blood culture report came out to be negative and antibiotics have been stopped. CSF examination was not performed. The laboratory reports of the baby have been summed up in supplementary table 2 . The baby had leukocytosis with positive C-reactive protein and raised Lactate dehydrogenase levels. The baby was discharged

\begin{tabular}{lcc} 
Table 1: Clinical laboratory findings of Case No $\mathbf{l}$ & \\
\hline Variable & Results on day $\mathbf{1}$ of admission & Results on day 7 \\
\hline Hemoglobin $(11-18 \mathrm{~g} / \mathrm{dl})$ & 15.6 & 15.2 \\
Total leucocyte count $\left(4-11 \times 10^{\circ} / \mathrm{L}\right)$ & 17.8 & 10.9 \\
Lymphocyte fraction $(21-48 \%)$ & 15.5 & 22.8 \\
platelet count $\left(150,000-450,000 \times\right.$ per $\left.\mathrm{mm}^{3}\right)$ & 151,000 & 140,000 \\
C-reactive protein $(0-0.6 \mathrm{mg} / \mathrm{ml})$ & 10.8 & 0.5 \\
Arterial blood gas analysis & $\mathrm{pH} 7.12$ & $\mathrm{pCo} 280$ \\
& $\mathrm{pO} 242$ & $\mathrm{HCO}-13$ \\
& $\mathrm{~K}+4.8$ & $\mathrm{Na}-132$ \\
& iCa 0.8 & 1.3 \\
Serum creatinine $(0.7-1.5 \mathrm{mg} / \mathrm{dl})$ & 6 cells \\
CSF analysis & $100 \%$ lymphocytes \\
& Total sugar 110 \\
Blood culture & Total protein 42 \\
Blood glucose $(45-126 \mathrm{mg} / \mathrm{dl})$ & no growth \\
Lactate dehydrogenase $(145-395 \mathrm{U} / \mathrm{L})$ & 112 \\
\hline
\end{tabular}




\begin{tabular}{l} 
Variable \\
\hline Hemoglobin $(11-18 \mathrm{~g} / \mathrm{dl})$ \\
Total leucocyte count $\left(4-11 \times 10^{9} / \mathrm{L}\right)$ \\
Lymphocyte fraction $(21-48 \%)$ \\
platelet count $\left(150,000-450,000 \times\right.$ per $\left.\mathrm{mm}^{3}\right)$ \\
C-reactive protein $(0-0.6 \mathrm{mg} / \mathrm{ml})$ \\
Serum creatinine $(0.7-1.5 \mathrm{mg} / \mathrm{dl})$ \\
Blood culture \\
Blood glucose $(45-126 \mathrm{mg} / \mathrm{dl})$ \\
Lactate dehydrogenase $(145-395 \mathrm{U} / \mathrm{L})$
\end{tabular}

Lactate dehydrogenase (145-395U/L)
Results on day 1 of admission

17.2

15.9

23.4

175,000

8.5

0.6

no growth

101
Results on day 7

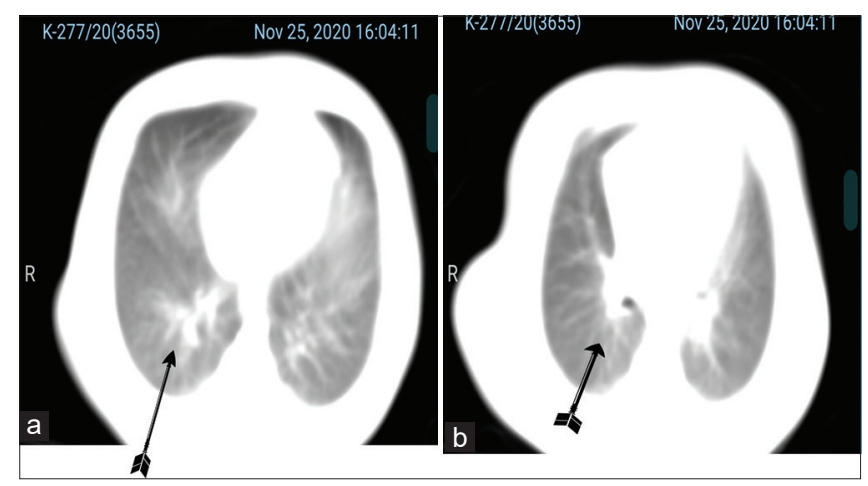

Figure 1: HRCT Lung shows bilateral ground glass appearance with perihilar streaking

after 5 days of hospital admission with suggested quarantine of 14days. Repeat RT-PCR was not done. The baby was asked to come for follow up after 14 days and found to be thriving well.

\section{CASE REPORT 3}

We report a third case with mother being COVID-19 positive by RT-PCR from upper nasopharyngeal swab at 39 weeks of gestation. She was having high grade intermittent fever with cough and cold. The mother (gravida 3, para2) delivered a healthy term baby boy of weight $3.2 \mathrm{~kg}$ by normal vaginal delivery. RT-PCR of the baby was sent within 24 hours of birth and was found to be negative. The mother-infant dyad was isolated from other patients and breastfeeding was started with full precautions. On day 3 of life the neonate developed physiological jaundice and was given phototherapy for 2 days. On follow up after 7 days the infant remained negative on repeat RT-PCT testing. Subsequently the baby was discharged and has been healthy on follow up after 14 days.

\section{DISCUSSION}

No evidence of transplacental transmission of COVID-19 could be proved in our study similar to previous study results. However there has been very few evidences of such in literature where SARS-COV-2 viruses have been isolated from amniotic fluid and placental tissues. ${ }^{5,6}$ As per WHO guidelines it is advisable to keep mother and neonate together for breastfeeding and initial bonding with proper use of effective masks and hand hygiene practice. ${ }^{7}$ However in low resource and low socioeconomic countries like India, it is very difficult to implement all these measures and one of our neonates contracted the disease in spite of parental education. Also, it is doubtful whether there is transmission of COVID-19 through breast milk which needs further research. A case report by Velasco et al showed presence of viral RNA in human breast milk. ${ }^{10}$ Due to economic constraints, we could not go for this test in our case 2 and thus we could not prove how the neonate contracted the disease from the mother which might be due to breast contamination through poor hand hygiene or due to presence of virus in the breast milk itself.

In our cases, we found a single case of COVID pneumonia that manifested as late onset sepsis. Similar case has been found in literature. ${ }^{10}$ The baby had leukocytosis with lymphopenia along with positive CRP. CSF examination was normal and blood culture was negative. The baby improved gradually though mechanical ventilation had to be given in our case. On follow up, we could not find any further complications and the baby was thriving well.

Thus, we can conclude from our study that the disease in newborn had mostly been mild or asymptomatic unlike adult population and outcomes had been favorable and this had been already evident from the literature ${ }^{8,9}$ further research work is needed for complete illustration of disease pathogenesis in neonates as well as possible vertical transmission in neonates.

\section{REFERENCES}

1. WHO Coronavirus disease (COVID-2019) Situation report 2020 Available at https://www.who.int/emergencies/diseases/novelcoronavirus-2019/situation-reports

2. Zhou F, Yu T, Du R, Fan G, Liu Z, et al. Clinical course and 
risk factors for mortaliy of adult inpatients with COVID-19 in Wuhan, China: a retrospective cohort study. Lancet. 2020:395(10229):1054-1062.

https://doi.org/10.1016/S0140-6736(20)30566-3

3. Lee PI, Hu YL, Huang YC and Hsueh PR. Are children less susceptible to COVID-19? J. Microbiol. Immunol Infect. 2020:53(3):371-372.

https://doi.org/10.1016/j.jmii.2020.02.011

4. Trevisanuto D, Cavallin F, Cavicchilo ME, Borellini M, Calgaro $S$ and Baraldi E.Coronavirus infection in neonates: a systematic review. Archives of Disease in Childhood - Fetal and Neonatal Edition Published Online First: 17 September 2020. https://doi.org/10.1136/archdischild-2020-319837

5. Zamaniyan M, Ebadi A, Aghajanpoor Mir S, Rahmani Z, Haghshenas $M$ and Azizi S. Preterm delivery in pregnant woman with critical COVID-19 pneumonia and vertical transmission. Prenat Diagn. 2020; (published online April 17.) https://doi.org/10.1002/pd.5713

6. Kirtsman M, Diambomba Y, Poutanen SM, Malinowski AK Vlachodimitropoulou E, Tony Parks W, et al. Probable congenital SARS-CoV-2 infection in a neonate born to a woman with active
SARS-CoV-2 infection. CMAJ. 2020; (published online May 14.) https://doi.org/10.1503/cmaj.200821

7. Clinical management of COVID-19. Interim guidance. World Health Organization. https://www.who.int/publications-detail/ clinical-management-of-severe-acute-respiratory-infectionwhen-novel-coronavirus-(ncov)-infection-is-suspected

8. Zeng L, Xia S, Yuan W, Yan K, Xiao F, Shao J, et al. Neonatal early-onset infection with SARS-CoV-2 in 33 neonates born to mothers with COVID-19 in Wuhan, China. JAMA Pediatr. 2020;174(7):722-725.

https://doi.org/10.1001/jamapediatrics.2020.0878

9. Nawaratne U, McMann D, Ellsworth M, Meliones J, Boukas K and Coronado Munoz A.Late-onset neonatal sepsis in a patient with Covid-19. N Engl J Med. 2020; 382: e49. https://doi.org/10.1056/NEJMc2010614

10. Velasco AH, Bobadilla-Montes de Oca PV, Garcia-Sosa LE, Zarate-Segura P, Reyes-Ruiz JM and Gonzalez B. A case report of newborn infant with severe COVID-19 in Mexico: Detection of SARS-CoV-2 in human breast milk and stool. Int J Infect Dis. 2020; 100: 21-24.

https://doi.org/10.1016/j.ijid.2020.08.055

Authors Contribution:

JS- Concept and designing the study, writing of manuscript; TD- Revision of manuscript; KN- treating physician, finalizing manuscript.

Work attributed to:

Department of Pediatrics, Burdwan Medical College

ORCID ID:

Dr. Jinia Saha- (D) https://orcid.org/0000-0003-2710-1082

Source of Support: None, Conflict of Interest: None. 